\title{
Natural organic matter (NOM) removal in a typical North-China water plant by enhanced coagulation: Targets and techniques
}

\author{
Mingquan Yan ${ }^{\mathrm{a}, *}$, Dongsheng Wang ${ }^{\mathrm{b}}$, Jinren $\mathrm{Ni}^{\mathrm{a}}$, Jiuhui $\mathrm{Qu}^{\mathrm{b}}$, Wenjin $\mathrm{Ni}^{\mathrm{c}}$, John Van Leeuwen ${ }^{\mathrm{d}}$ \\ a Department of Environmental Engineering, College of Environmental Sciences and Technology, Peking University, Beijing 100781, China \\ b State Key Laboratory of Environmental Aquatic Chemistry, Research Center for Eco-Environmental Sciences, Chinese Academy of Sciences, POB 2871, Beijing 100085, China \\ ' Safe Drinking Water Center for Ruralarea, The Minstry of Water Source, 100053, China \\ d Division of Information Technology, Engineering and the Environment, School of Natural and Built Environments, University of South Australia, \\ Mawson Lakes Campus H3-26, Australia
}

\section{A R T I C L E I N F O}

\section{Article history:}

Received 16 January 2009

Received in revised form 15 May 2009

Accepted 25 May 2009

\section{Keywords:}

Composite polyaluminum chloride (HPAC)

Magnesium

$\mathrm{pH}$

Trihalomethanes formation potential

(THMFP)

Turbidity

\begin{abstract}
A B S T R A C T
Seasonal coagulation objectives for a typical North-China water treatment plant with micro-polluted and high alkalinity source waters are proposed in this paper. These are based on a yearlong data collection period where raw water characteristics, trihalomethanes formation potential (THMFP) and coagulation features were investigated using a jar test procedure, resin absorption and ultrafiltration fractionations. Three approaches beyond simply increasing the coagulant dose were used to achieve optimized coagulation. One is coagulation by adjusting the $\mathrm{pH}$ of the raw water when metal salt coagulants $\left(\mathrm{FeCl}_{3}\right.$ and $\left.\mathrm{AlCl}_{3}\right)$ are used. At pH levels of about 5.0 for $\mathrm{FeCl}_{3}$ and about 5.8 for $\mathrm{AlCl}_{3}$, the highest removal of natural organic matter (NOM) was obtained, which is twice that without $\mathrm{pH}$ control. The second is enhanced coagulation through coagulant optimization based on raw water characteristics. A high efficient composite polyaluminum chloride (HPAC) coagulant was developed for the water taking the advantages of polyaluminum chloride (PACl) and other additives. HPAC exhibited 30\% more efficiency than $\mathrm{AlCl}_{3}, \mathrm{FeCl}_{3}$ and polyaluminum chloride (PACl) in dissolved organic carbon (DOC) removal and was also very effective in turbidity removal. The third is enhanced softening with coagulant addition. Higher removal of NOM is achieved by enhanced softening with coagulant addition conditions as compared with conventional coagulation at natural $\mathrm{pH}$. Especially with $\mathrm{PACl}$ addition, it can enhance the formation of $\mathrm{Mg}(\mathrm{OH})_{2}$ precipitate and remove NOM efficiently at a relatively lower $\mathrm{pH}$ range $(\mathrm{pH}<10)$. By this approach, the $\mathrm{pH}$ for enhanced softening can be decreased significantly into a practical operation $\mathrm{pH}$ range for high-hardness water at a treatment plant.
\end{abstract}

(C) 2009 Elsevier B.V. All rights reserved.

\section{Introduction}

Coagulation and flocculation are important steps in the treatment of water for drinking purposes, allowing the removal of particles and natural organic matter (NOM). Historically, most coagulation processes were primarily designed for particle and turbidity removal. Only some plants, especially those having to treat highly colored water, were primarily designed to remove NOM. NOM can cause many problems such as odor, taste, color, transportation of hydrophobic contaminants and bacterial regrowth in the distribution systems. It is now well recognized that NOM in drinking water can react with oxidative chemicals during treatment processes, resulting in the formation of trihalomethanes (THMs), haloacetic acids (HAAs), and a lot of other halogenated disinfection by-products (DBPs) [1].

\footnotetext{
* Corresponding author. Tel.: +86 1062755914 81; fax: +86 1062756526 .

E-mail address: Yanmq@pku.edu.cn (M. Yan).
}

The US Environmental Protection Agency (USEPA) has established maximum contaminant levels for the sum of four THMs and five HAAs at 80 and $60 \mu \mathrm{g} \mathrm{L}^{-1}$, respectively in US drinking waters and has mandated that water utilities remove NOM as a means to reduce DBP precursors [2]. Enhanced coagulation and enhanced softening were selected by USEPA as the stage 1 treatments of choice because it is effective for the removal of total organic carbon (TOC) and can be implemented at most water utilities using existing treatment processes [2]. The approach includes two steps. Step 1 defines the percentage TOC removal by the plant based on the raw water TOC and alkalinity levels. If it is technically unfeasible to meet the TOC removal requirements in stage 1 , the plant operators can follow the second step of the D/DPB rule for alternative performance criteria. In step 2, jar testing is required to assess TOC removal. For enhanced coagulation, alum (or an equivalent dose of ferric coagulant) is added in $10 \mathrm{mg} \mathrm{L}^{-1}$ increment until the $\mathrm{pH}$ is lowered to a target $\mathrm{pH}$ value (based on the alkalinity of the raw water). The TOC removal is then plotted versus coagulant dose and the 'point of diminishing return' is defined as the dose wherein the last $10 \mathrm{mg} \mathrm{L}^{-1}$ 
addition of alum, or equivalent dose of other coagulant, results in less than $0.3 \mathrm{mg} \mathrm{L}^{-1}$ removal of TOC is then used as an alternative minimum TOC removal criteria. For enhanced softening, plants that remove more than $10 \mathrm{mg} \mathrm{L}^{-1} \mathrm{Mg}$ hardness as $\mathrm{CaCO}_{3}$ are proposed to be exempted from the enhanced softening requirements in the step 1 by the USEPA [2].

Applying increased dosages of coagulants and the control the raw water $\mathrm{pH}$ by addition of acid or base are two common options to enhance NOM removal. However, both of these methods have some disadvantages, such as increasing the corrosive tendency of the water and treatment costs [2-4].

With rapid industrial development and economic expansion, drinking water sources in China have become ubiquitously polluted by organic contaminants. Chinese governments and communities recognize the importance of safe drinking water and are making great efforts to ensure its safety. This study is part of these efforts, which aims to improve current water treatment performance by coagulation optimization. Typical water sources in North-China were used to conduct this study. The main objectives were as follows: (1) determine the water quality characteristics of drinking water sources in North-China; (2) determine the coagulation characteristics of the waters and the optimized coagulation criteria for the water; and (3) demonstrate efficient measures to improve NOM removal by coagulation.

\section{Materials and methods}

\subsection{Materials}

All the reagents used were of analytical grade, except those otherwise specified. The two coagulants, aluminum chloride $\left(\mathrm{AlCl}_{3}\right)$ and ferric chloride $\left(\mathrm{FeCl}_{3}\right)$ used in bench scale tests were reagent grade (Chemical Regent Co., Tianjin, China). The $\mathrm{FeCl}_{3}$ (with $\mathrm{Fe}_{2} \mathrm{O}_{3}$ content of $40 \%), \mathrm{AlCl}_{3}, \mathrm{NaSiO}_{3}$, and polydiallyldimethyl ammonium chloride (PDADMAC) used in pilot-plant trials were made by a local company (Tianjin Tianshui Water Cleaning Agent Co., China). Polyaluminum chloride ( $\mathrm{PACl}$ ) and a novel composite polyaluminum chloride (HPAC) (both with $10 \% \mathrm{Al}_{2} \mathrm{O}_{3}$ content) were produced by a company (Beijing Wanshui Water Cleaning Agent Co., China) using a technique developed in our laboratory. PACl was produced by forced aluminum hydrolysis with alkali addition; the basicity $(\mathrm{OH} / \mathrm{Al}$ molar ratio $)$ is about 1.6. HPAC was prepared from $\mathrm{PACl}$ and other organic and inorganic additives such as active silicates and PDADMAC $[5,6]$.

\subsection{Jar and pilot-scale tests}

Jar tests were performed with $1 \mathrm{~L}$ of raw water in 1.4 -L beakers with a sampling port located $3 \mathrm{~cm}$ below the water surface. A programmable jar testing apparatus (Daiyuan Jar Test instruments, China) was used with the following procedure: addition of coagulant followed by $30 \mathrm{~s}$ rapid mixing at $300 \mathrm{rpm}\left(G=172.1 \mathrm{~s}^{-1}\right)$, $2 \mathrm{~min}$ rapid mixing at $250 \mathrm{rpm}\left(G=134.4 \mathrm{~s}^{-1}\right), 10 \mathrm{~min}$ flocculation at $40 \mathrm{rpm}\left(G=11.3 \mathrm{~s}^{-1}\right)$ and $20 \mathrm{~min}$ settling. Treated water samples were taken after settling for later analyses. The $\mathrm{pH}$ was adjusted (if needed) by predetermined amount of $\mathrm{HCl}$ or $\mathrm{NaOH}$, which was dosed 30 s before adding coagulant, during rapid mixing period. Coagulant dosages were measured using a calibrated pipette.

Pilot-scale tests were performed with two parallel systems, including coagulation, flocculation, dissolved air flotation, and sand filtration. The flow rate of each system was controlled at $5 \mathrm{~m}^{3} \mathrm{~h}^{-1}$. The coagulation process was carried out using the following conditions, rapid mixing ( $t=1 \mathrm{~min}$ and $G=756 \mathrm{~s}^{-1}$ ) and two-stage flocculation (in each stage, $t=9 \mathrm{~min}$ and $G=91.5 \mathrm{~s}^{-1}$ ). The surface loading rate of flotation was $11 \mathrm{~m}^{3} \mathrm{~m}^{-2} \mathrm{~h}^{-1}$, the recycle ratio was
$10 \%$ and the saturator pressure was $400 \mathrm{kPa}$, residence time was $126 \mathrm{~s}$. The depth of the sand filtration bed was $2.7 \mathrm{~m}$ and the filtration rate was $7.86 \mathrm{~m} \mathrm{~h}^{-1}$. The sand filter medium was sand of $400 \mathrm{~nm}$ average diameter. The details of the pilot-plant have been previously reported $[5,6]$.

\subsection{Analytical methods}

Total organic carbon (TOC) was analyzed using a Phoenix 8000 system (Tekmar-Dohrman Co., USA). Dissolved organic carbon (DOC) was analyzed after filtration through a $0.45 \mu \mathrm{m}$ membrane. $\mathrm{UV}_{254}$ was measured by a spectrophotometer (UV-VIS 8500 , China) after filtration through a $0.45 \mu \mathrm{m}$ membrane. Turbidity was measured using a $2100 \mathrm{~N}$ Turbidimeter (Hach, USA). pH was measured by a pHS-3C (Shanghai, China) pH meter, which was calibrated daily. Alkalinity, THMFP and chemical oxygen demand $\left(\mathrm{COD}_{\mathrm{Mn}}\right)$ were measured by standard methods [7]. DOC was characterized using resin absorption and ultrafiltration (UF) fractionation methods, as described elsewhere [8].

\section{Results and discussion}

\subsection{Water characteristics}

\subsubsection{Water quality}

The source water for a typical northern China water treatment plant, Jieyuan Water Treatment Plant (WTP) was selected for this study. The source water for Jieyuan WTP changes seasonally. In the rainy seasons, summer and autumn, the source water is from the Luanhe River (LW). The Luanhe River is a local river running through industrial and residential areas. In the dry seasons, spring and winter, the Luanhe River is short of water and the plant takes in downstream water from the Yellow River (YW). The Yellow River is one of the two largest rivers in China. It runs through several geological areas from west to east of China.

The quality of the source water of Jieyuan WTP has changed regularly with season in the past three years, as exemplified by the daily water quality reports in one year shown in Fig. 1 (provided by the water company). The alkalinity was generally about $110 \mathrm{mg} \mathrm{L}^{-1}$ as $\mathrm{CaCO}_{3}$, and for YW, it was as high as $200 \mathrm{mg} \mathrm{L}^{-1}$ as $\mathrm{CaCO}_{3}$. The $\mathrm{pH}$ was up to 8.1. Turbidity and algae were found to be strongly dependent on temperature. The increase of turbidity in summer and early autumn was mainly due to algal blooms during those periods.

Based on the source water quality trends, one year could be divided into six different periods, i.e. (1) low temperature and turbidity: Yellow River water (LTTY, December and January); (2) spring Yellow River water (SprY, from February to April); (3) early summer Yellow River water (ESumY, latter April and early May); (4) early summer Luanhe River water (ESumL, from May to July); (5) high temperature and algae: Luanhe River water (HTAL, from July to October); and (6) autumn Yellow River water (AutY, October and November).

\subsubsection{NOM characteristics}

NOM in LW and YW were characterized using resin adsorption and UF fractionation methods. Partial results are shown in Fig. 2.

The fraction with a molecular weight of less than $10 \mathrm{kDa}$ is more than $80 \%$ of the DOC in LW and YW. Particularly in LW, the DOC with molecular weight less than $1 \mathrm{kDa}$ is the greatest fraction, which accounts for about 60\% in Jun LW. While in YW, the DOC with molecular weight in the range of $1-10 \mathrm{kDa}$ is the greatest fraction. Although the percentage of hydrophobic DOC is highest in Nov YW, as high as $60 \%$, which is less than the ordinary value of more than $70 \%$ [8-10]. The data suggests that the water in North-China is polluted by hydrophilic and low molecular weight DOC. 


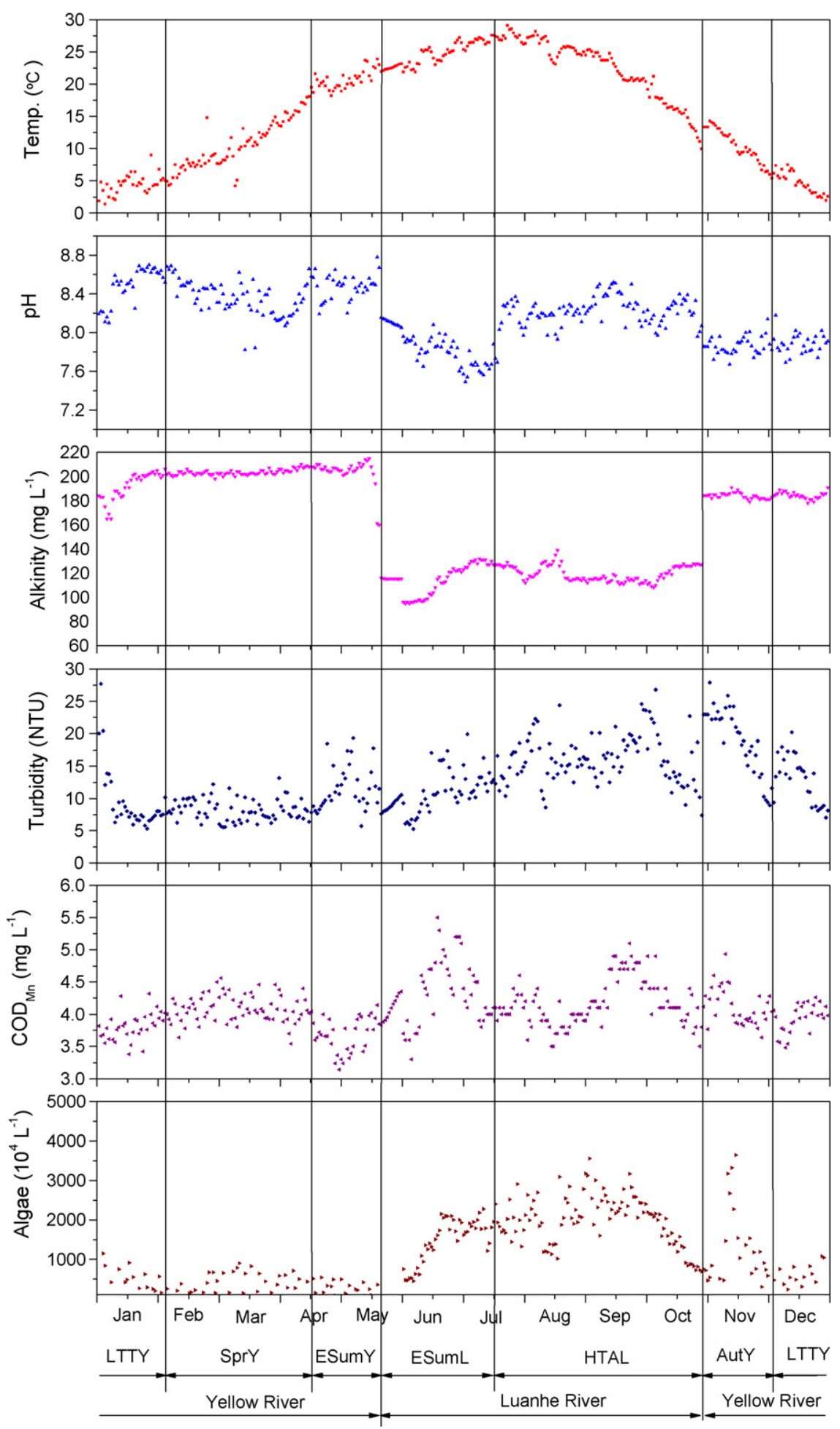

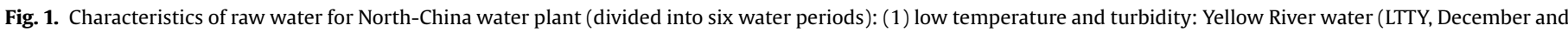

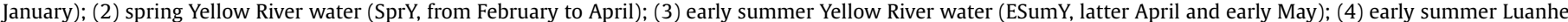

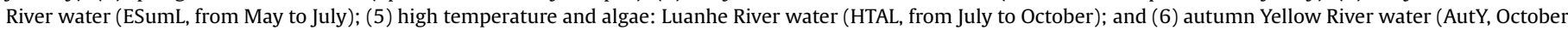
and November).

\subsubsection{THMFP of NOM}

The THMFP of YW in April is shown in Fig. 3. The DOC with low molecular weight has higher THMFP (Fig. 3a). Fig. 3b shows that not only the hydrophobic acid but also the hydrophilic have higher THMFP. The result shows that if the organic is hydrophilic and low molecular weight organic pollution is very likely to have higher THMFP, thus it could pose health issue of the formation of DBPs in disinfection process with $\mathrm{Cl}_{2}$ $[11,12]$.

\subsection{Seasonal variation of coagulation feature}

Coagulation of the North-China water was studied during a year period and the results using the coagulant $\mathrm{FeCl}_{3}$ in the six 

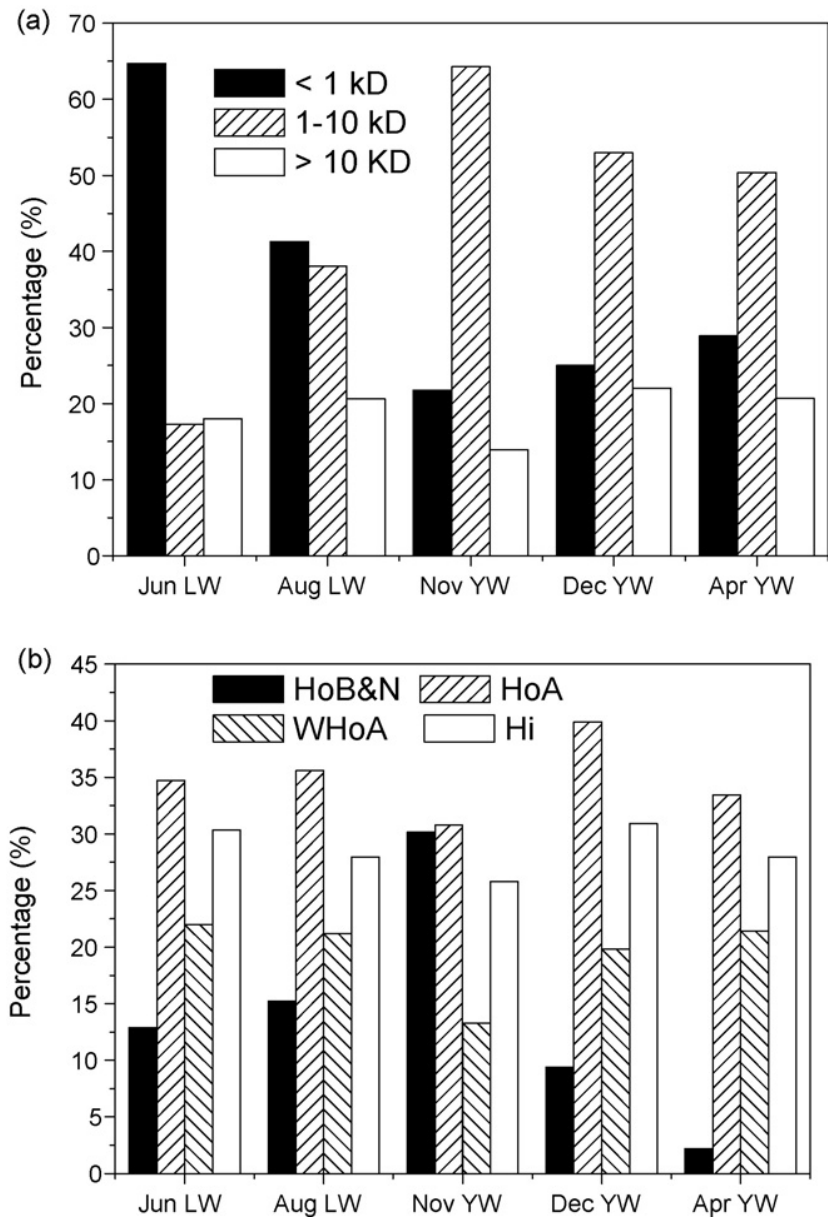

Fig. 2. Comparison of NOM by (a) ultrafiltration and (b) resin absorbent in the Yellow River water (YW), hydrophobic basic and neutral (HoB\&N), hydrophobic acid (HoA), weakly hydrophobic acid (WHoA), and hydrophilic (Hi).

water periods are shown in Fig. 4. The coagulation performance exhibited seasonal influences. LW was easier to treat than YW in terms of both $\mathrm{UV}_{254}$ and turbidity removal. For YW, the coagulation performance changed with season also. Higher temperatures resulted in higher coagulation efficiencies in $U_{254}$ removal. Higher $U_{254}$ removal from raw waters in different periods occurred in the following sequence: AutY, ESumY > SprY > LTTY. Although the optimal dosages for turbidity removal are the same (about $0.04 \mathrm{mM}$ ) for all raw waters, the residual turbidity changes seasonally. For LW, although the raw turbidities differ greatly, residual turbidities could reach almost the same low. While for YW, residual turbidities changed greatly in different seasons, and more efficient removal occurred for SprY and AutY.

From Fig. 4, we can see that the dosage for turbidity removal is less than that for $\mathrm{UV}_{254}$ removal. In natural water, the dosage of coagulant for organic matter removal is determined by the anionic charge of dissolved organics, which must be neutralized or partly neutralized. The historical measure to determine coagulant dosage based on turbidity is not satisfactory, and at which the removal of NOM may not be adequate.

$\mathrm{UV}_{254}$ removal is affected by many factors, particularly alkalinity, temperature and NOM characteristics.

Many researchers have found that for high $\mathrm{pH}$ water with lower alkalinity, the NOM is removed more efficiently $[13,14]$. LW is of lower alkalinity than YW and the NOM in it was removed more efficiently. The reason that alkalinity is an important factor influencing the performance of coagulation could be explained by the alkalinity in controlling the $\mathrm{pH}$ of coagulation after coagulant addition, and further in controlling the hydrolyzed species of metal coagulants. The higher the alkalinity, the further the extent of the hydrolysis process, formation of larger polymers and more precipitation that occurs. These are not necessarily beneficial for maximizing NOM removal [6].

The temperatures affect the concentration of $\mathrm{OH}^{-}$present for metal salt hydrolysis and the hydrolysis kinetics of metal salts [15]. The performances of three traditional coagulants were compared at different seasons and it was found that pre-hydrolyzed aluminum chloride could improve the efficiency of coagulation, especially for NOM removal at various temperatures. At low temperature, the removal of $\mathrm{UV}_{254}$ by $\mathrm{PACl}$ was not affected significantly, in contrast to $\mathrm{AlCl}_{3}$ and $\mathrm{FeCl}_{3}$ (data not shown in this paper).

Although the $\mathrm{COD}_{\mathrm{Mn}}$ did not change obviously in the year (about $3-5 \mathrm{mg} \mathrm{L}^{-1}$ ), the change in NOM character shows great different in coagulation performance [8].

\subsection{Coagulation targets}

Enhanced coagulation of North-China water was studied, based on the USEPA jar test protocol [2] using the coagulant aluminum chloride $\left(\mathrm{AlCl}_{3}\right)$. The results for the water periods, ESumL and AutY, are shown in Fig. 5. The dosage of $\mathrm{AlCl}_{3} \cdot 6 \mathrm{H}_{2} \mathrm{O}$ is shown in Fig. 5 was transformed to $\mathrm{Al}_{2}\left(\mathrm{SO}_{4}\right)_{3} \cdot 14 \mathrm{H}_{2} \mathrm{O}$, based on $\mathrm{Al}$ ion.

A TOC removal efficiency of $20.8 \%$ at a dosage of $30 \mathrm{mg} \mathrm{L}^{-1}$ for ESumL (arrow B), and 9.5\% at a dosage of $18 \mathrm{mg} \mathrm{L}^{-1}$ (arrow A) for AutY should be attained if the second step of the USEPA Enhanced
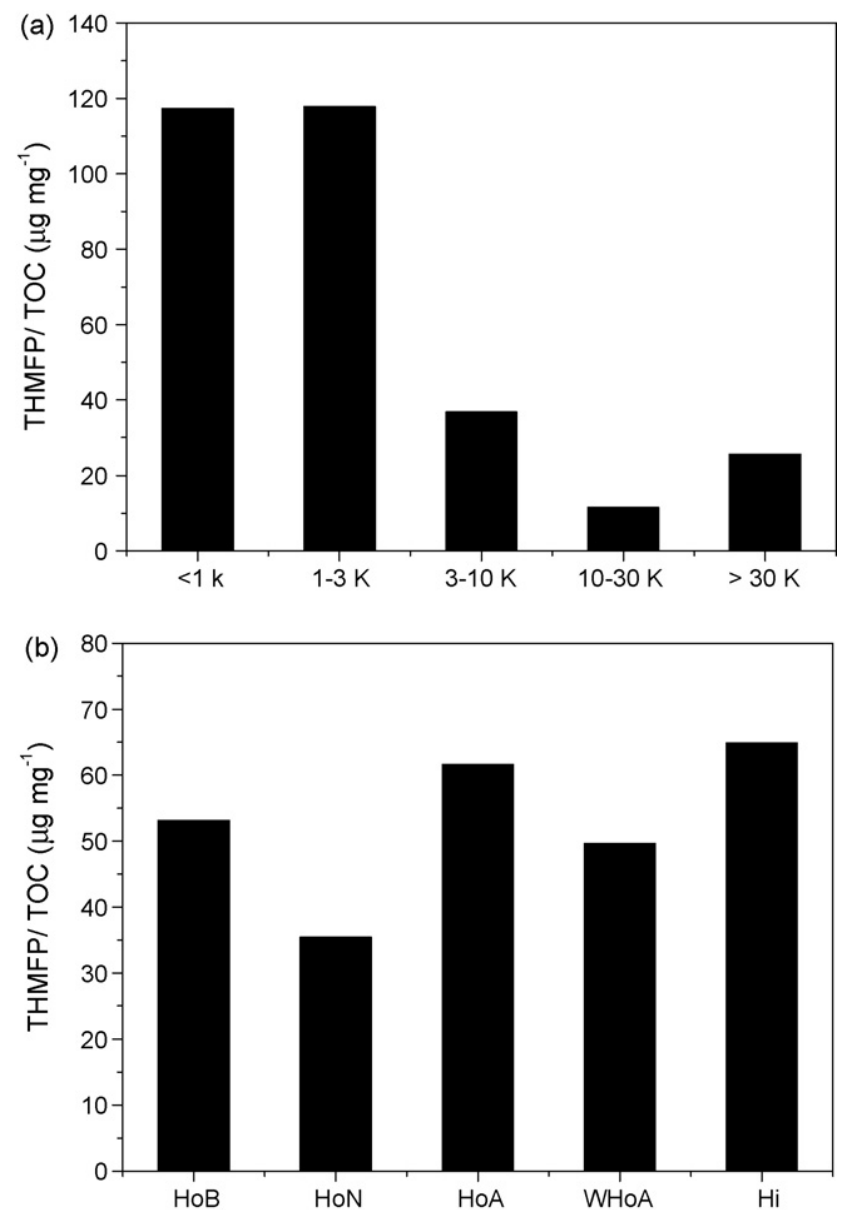

Fig. 3. Trihalomethanes formation potential of NOM fraction in the Yellow River water (YW): (a) ultrafiltration and (b) resin absorbent. Hydrophobic basic (HoB), hydrophobic neutral (HoN), hydrophobic acid (HoA), weakly hydrophobic acid (WHoA), and hydrophilic (Hi). 

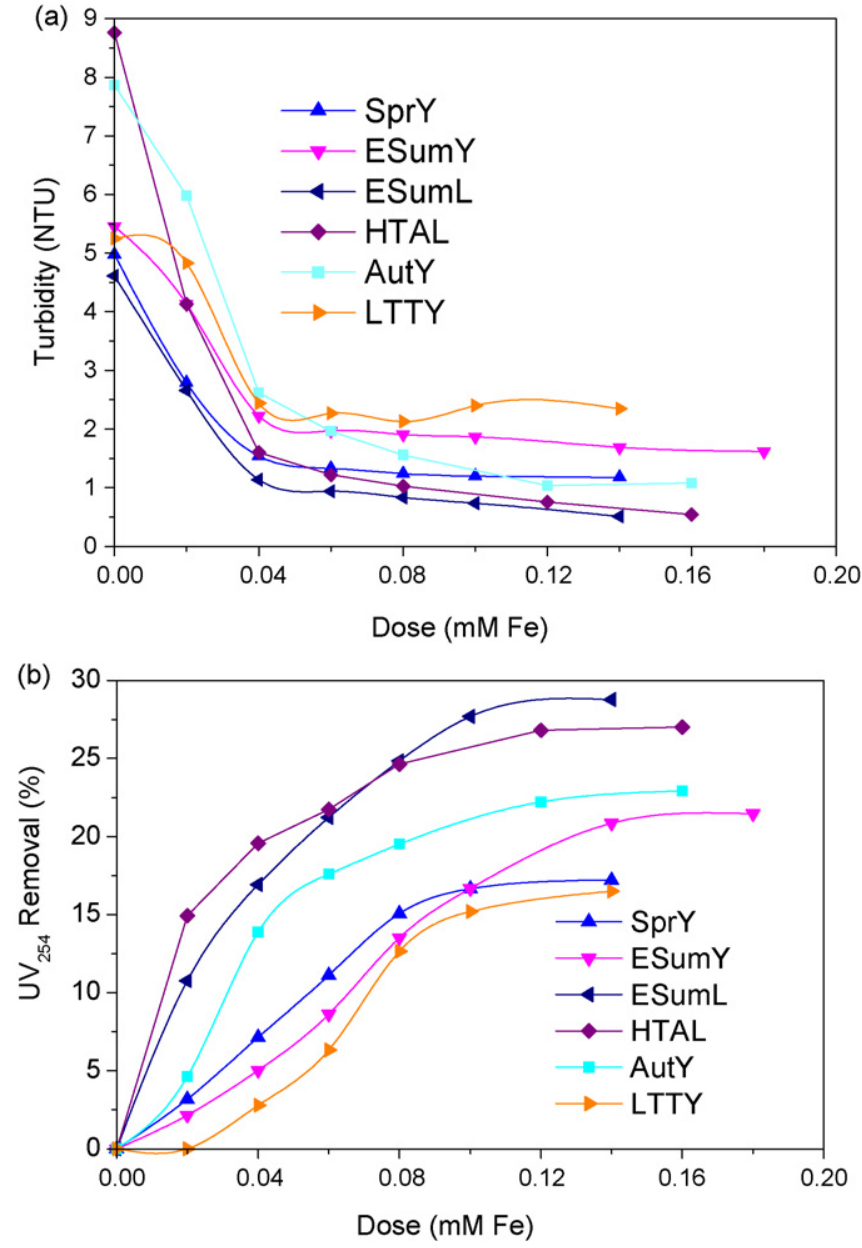

Fig. 4. The comparison of $\mathrm{UV}_{254}$ and turbidity removal seasonally by coagulant $\mathrm{FeCl}_{3}$ in Jar test: (a) residual turbidity and (b) $\mathrm{UV}_{254}$ removal.

Coagulation standard was adopted, i.e. continue dosing to achieve a TOC removal of $0.3 \mathrm{mg} \mathrm{L}^{-1}$ per increasing $10 \mathrm{mg} \mathrm{L}^{-1}$ coagulant (as shown as the line USEPA in Fig. 5). These percentages are very low, and USEPA Enhanced coagulation standard is not suitable for these kinds of high alkalinity and seriously polluted waters.

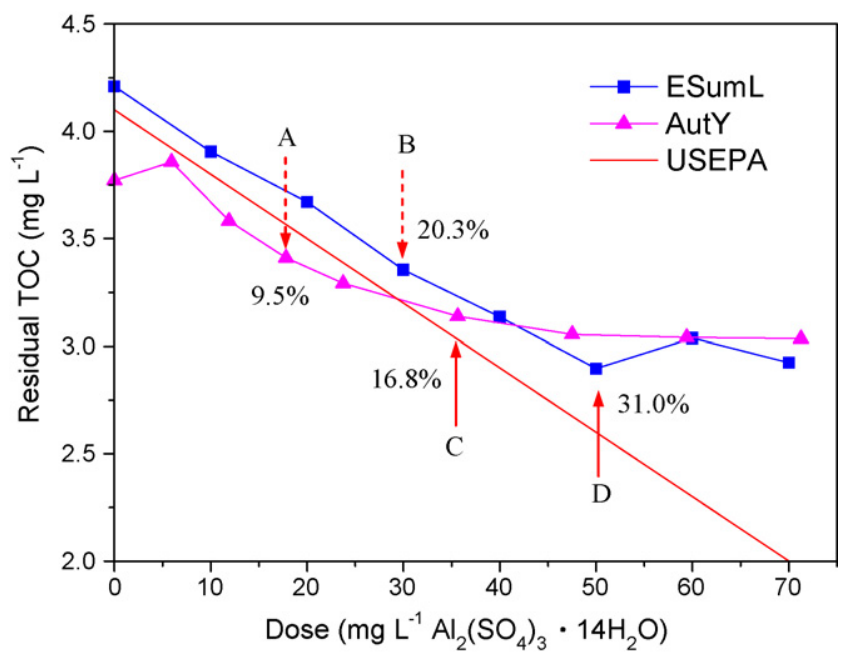

Fig. 5. The comparison of TOC removal by $\mathrm{AlCl}_{3}$ for AutY and ESumL referring the USEPA protocol jar test.

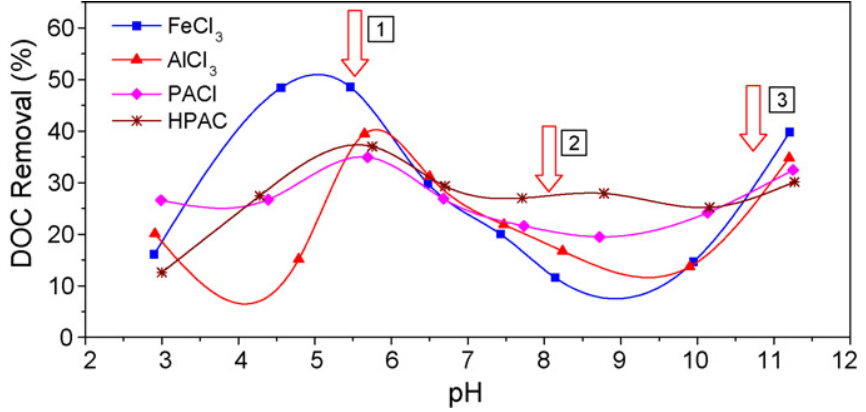

Fig. 6. The effect of $\mathrm{pH}$ on $\mathrm{DOC}$ removal by coagulants, $\mathrm{FeCl}_{3}, \mathrm{AlCl}_{3}, \mathrm{PACl}$ and $\mathrm{HPAC}$ at dosage $0.08 \mathrm{mM}$ for the Yellow River water in autumn.

For ESumL, when the dosage was increased up to $50 \mathrm{mg} \mathrm{L}^{-1}$ $\mathrm{Al}_{2}\left(\mathrm{SO}_{4}\right)_{3} \cdot 14 \mathrm{H}_{2} \mathrm{O}$ (arrow D), the TOC removal reached $31.0 \%$. With further increases in the dosage, the TOC removal increased only slightly. For AutY, when the dosage was $23 \mathrm{mg} \mathrm{L}^{-1}$ (arrow C), the residual TOC was still decreasing slowly, but the residual turbidity began to increase, indicating that re-stabilization had occurred (data not shown). As the dose increased up to more than $35 \mathrm{mg} \mathrm{L}^{-1}$, the removal rate of TOC slowed and the residual turbidity increased significantly.

There are two ways to optimize coagulant dosing. One is to select the lowest dose to achieve aims in residual TOC, turbidity, color and so on; the other is the dose that gives the highest removal efficiencies for the lowest coagulant dosage. According the latter, the optimum for TOC removal should be $31.0 \%$ at the dosage of $50 \mathrm{mg} \mathrm{L}^{-1}$ for ESumL, and $16.8 \%$ at the dosage of $35 \mathrm{mg} \mathrm{L}^{-1}$ for AutY. It should to note that the above does not mean that these doses should be used in water plant, and the removal efficiency of TOC refers to the portion of NOM that could be removed by coagulation economically.

Many researchers have found that the $\mathrm{UV}_{254}$ absorbance correlates to the concentration of NOM in water, especially the aromatic carbon content $[11,16]$. This fraction of NOM can more easily react with oxidants to produce DBPs. Edzwald et al. [11] and Weishaar et al. [17] found $U_{254}$ is a good surrogate parameter for monitoring organic matter and disinfection by-products formation potential. The measurement of $U_{254}$ is quick and easy for operation and is suitable for routine monitoring at a WTP.

Based on the results shown in Fig. 2, the seasonal coagulation targets for NOM removal for the North-China water plant are set with parameter $\mathrm{UV}_{254}$. The corresponding parameter of turbidity is also given for reference, in Table 1.

\subsection{Strategies for NOM removal}

The concentration of $\mathrm{OH}^{-}$in water should determine the degree of hydrolysis and hydrolysis products of metal salt coagulants, $\mathrm{AlCl}_{3}$ and $\mathrm{FeCl}_{3}$ that affect performance of these coagulants in coagulation process $[15,18]$. The effect of $\mathrm{pH}$ on DOC removal by four typical coagulants $\mathrm{FeCl}_{3}, \mathrm{AlCl}_{3}, \mathrm{PACl}$ and $\mathrm{HPAC}$ in the $\mathrm{pH}$ range of 3-12 was investigated. The results at doses of $0.08 \mathrm{mM} \mathrm{Al} / \mathrm{Fe}$ are shown in Fig. 6.

As shown in Fig. 6, the optimum pH for $\mathrm{AlCl}_{3}, \mathrm{PACl}$ and $\mathrm{HPAC}$ is about 5.8, and the optimum $\mathrm{pH}$ for $\mathrm{FeCl}_{3}$ is about 5.0. Especially for $\mathrm{AlCl}_{3}$ and $\mathrm{FeCl}_{3}$, these are very efficient for NOM removal at their optimum $\mathrm{pH}$, but their performances can be affected significantly by $\mathrm{pH}$. Those deteriorate obviously at neutral and basic $\mathrm{pH}$ range. However for some high alkalinity and $\mathrm{pH}$ waters, the $\mathrm{pH}$ is at about 7.5 , even higher than 8.0, at which the efficiency of DOC removal would is very low. 
Table 1

The seasonal coagulation aims for North-China water.

\begin{tabular}{|c|c|c|c|c|c|c|c|c|c|c|c|}
\hline & \multicolumn{5}{|c|}{ Raw water } & \multicolumn{3}{|c|}{ Traditional aims } & \multicolumn{3}{|c|}{ Optimized aims } \\
\hline & $T\left({ }^{\circ} \mathrm{C}\right)$ & $\mathrm{pH}$ & $\begin{array}{l}\text { Alkali. } \\
\left(\mathrm{mg} \mathrm{L}^{-1}\right)\end{array}$ & $\begin{array}{l}\text { Turb. } \\
\text { (NTU) }\end{array}$ & $\mathrm{UV}_{254}$ & Dose $(\mathrm{mM})$ & $\begin{array}{l}\text { Turb. } \\
\text { (NTU) }\end{array}$ & $\mathrm{UV}_{254}$ removal (\%) & Dose (mM) & $\begin{array}{l}\text { Turb. } \\
\text { (NTU) }\end{array}$ & $\begin{array}{l}U_{254} \text { removal } \\
(\%)\end{array}$ \\
\hline SprY & 17.0 & 8.6 & 200 & 4.90 & 0.126 & 0.04 & 1.54 & 7.0 & 0.10 & 1.2 & 16.5 \\
\hline ESumY & 22.5 & 8.49 & 194 & 5.46 & 0.139 & 0.04 & 2.23 & 5.0 & 0.14 & 1.7 & 20.0 \\
\hline ESumL & 22.5 & 8.10 & 115 & 4.61 & 0.065 & 0.04 & 1.14 & 17.0 & 0.10 & 0.75 & 27.5 \\
\hline HTAL & 25.6 & 8.18 & 115 & 8.76 & 0.069 & 0.04 & 1.60 & 20.0 & 0.12 & 0.8 & 27.0 \\
\hline AutY & 13.0 & 7.72 & 185 & 7.87 & 0.108 & 0.06 & 1.96 & 17.5 & 0.12 & 1.0 & 22.5 \\
\hline LTTY & 3.5 & 7.67 & 166 & 5.25 & 0.079 & 0.04 & 2.44 & $<5.0$ & 0.10 & 2.4 & 15.0 \\
\hline
\end{tabular}

As shown in Fig. 6, the effect of $\mathrm{pH}$ on DOC removal by HPAC and $\mathrm{PACl}$ as coagulant is less than metal salts because polymeric aluminum species pre-formed in HPAC and PACl are less affected by $\mathrm{pH}[14,19]$, especially for HPAC. The HPAC results are likely due to the nature of the polymerized $\mathrm{Al}$ species but also the presence of the synthetic cationic polymer which would not be affected by $\mathrm{pH}$ so should improve NOM removal relative to the standard $\mathrm{PACl}$. Although they are less efficient than $\mathrm{FeCl}_{3}$ and $\mathrm{AlCl}_{3}$ in acid condition, they are more efficient in basic condition. Thus they are more efficient for waters with high $\mathrm{pH} /$ alkalinity such as North-China water.

With $\mathrm{pH}$ further increased to 11, NOM removal efficiency increased again. At which the process becomes enhanced soften-
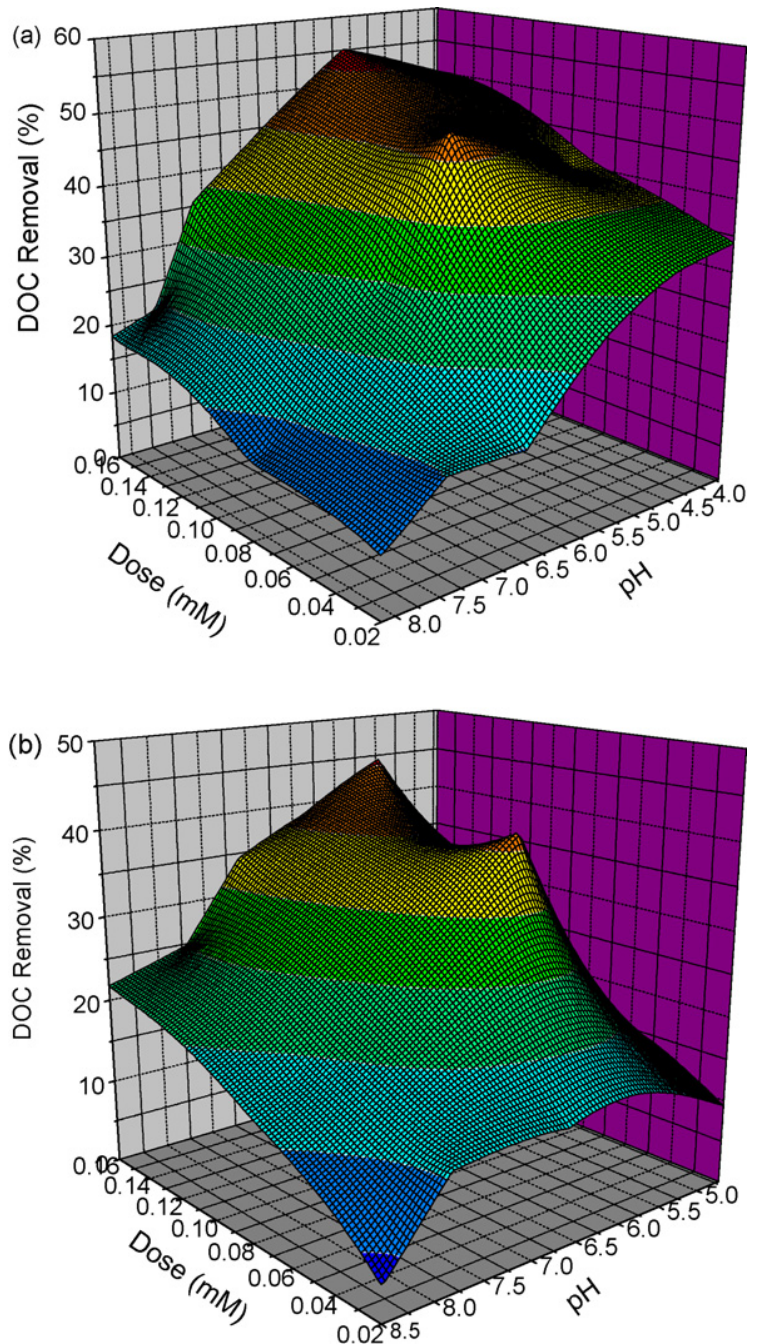

Fig. 7. The effect of $\mathrm{pH}$ and dose on NOM removal for the Yellow River water in autumn: (a) for coagulant $\mathrm{FeCl}_{3}$ and (b) for coagulant $\mathrm{AlCl}_{3}$. ing and the NOM is removed by co-precipitate of $\mathrm{Mg}(\mathrm{OH})_{2}$ and coagulants.

As discussed above, for high alkalinity water, there are three strategies that can go beyond increasing coagulant dose to enhance NOM removal. These are coagulation using metal salts with $\mathrm{pH}$ control, coagulant optimization, and enhanced softening with coagulant.

\subsection{1. $\mathrm{pH}$ control}

$\mathrm{pH}$ control is a common technique applied to enhance NOM removal [2]. The effect of pH on DOC removal by coagulants $\mathrm{FeCl}_{3}$, $\mathrm{AlCl}_{3}$ for North-China source waters was investigated. The effect of $\mathrm{pH}$ and coagulant dose on $\mathrm{DOC}$ removal by $\mathrm{FeCl}_{3}$ and $\mathrm{AlCl}_{3}$ was
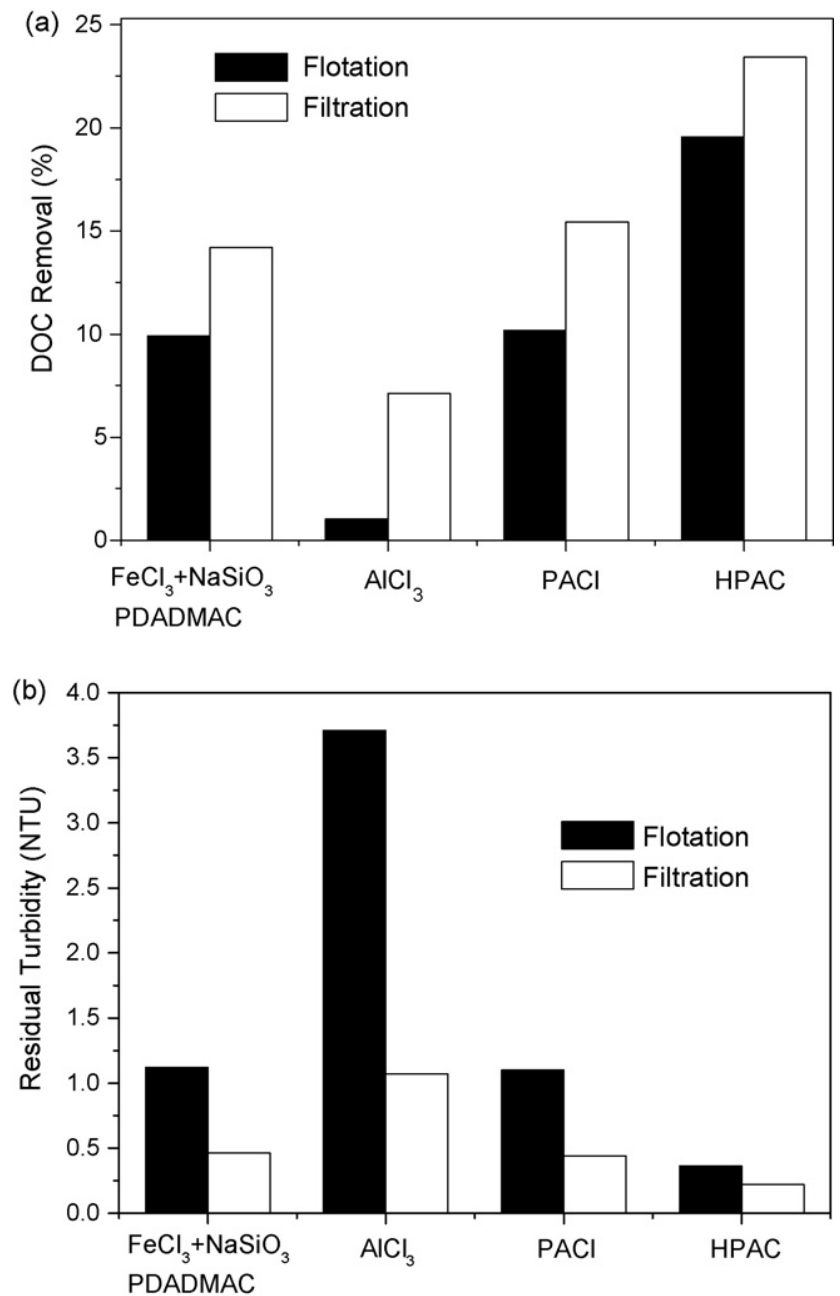

Fig. 8. The comparison of TOC and turbidity removal by four coagulants $\mathrm{AlCl}_{3}, \mathrm{PACl}$ and HPAC compared with traditional coagulants strategy in pilot-scale test for the Luan River water in summer. 

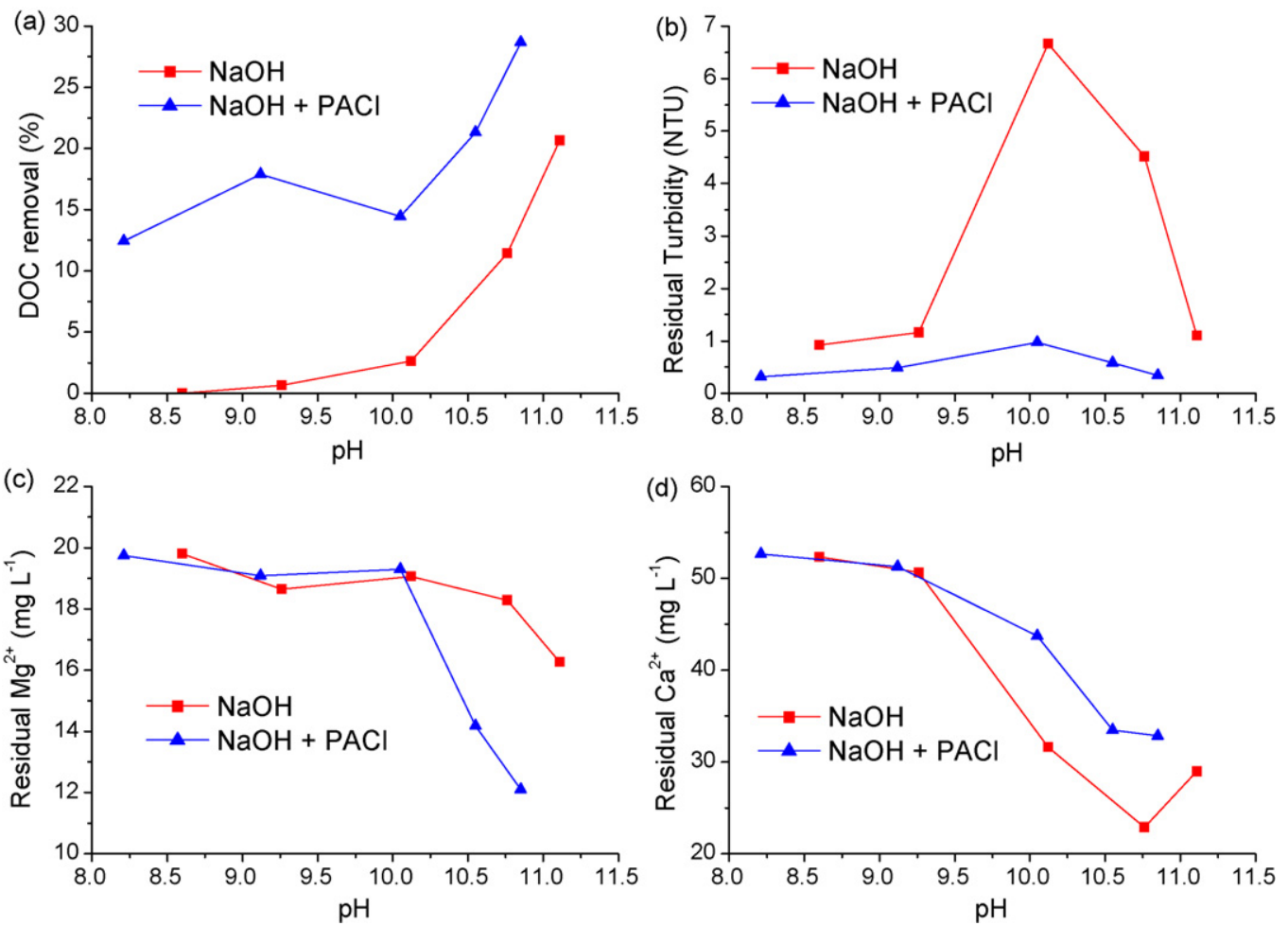

Fig. 9. The effect of $\mathrm{PACl}$ on softening by $\mathrm{NaOH}$ for the Luan River water in winter.

shown in Fig. 7. It shows that adjusting $\mathrm{pH}$ before coagulation with coagulants $\mathrm{FeCl}_{3}$ and $\mathrm{AlCl}_{3}$ is a good measure to enhanced NOM removal, particularly with $\mathrm{FeCl}_{3}$.

Unfortunately, $\mathrm{pH}$ control has some disadvantages [4]. The first is that it could increase the corrosive tendency of treated water. Secondly, the addition of acid and base for $\mathrm{pH}$ control would increase the operational costs. The third is that it would increase the complexity of water treatment operation and facility.

\subsubsection{Coagulant optimization}

The technique to treat high alkalinity and micro-polluted waters through coagulant optimization has been reported in a previous paper [6]. DOC and turbidity removal correlated well with the hydrolyzing behavior of the coagulants with the minimum solubility of $\mathrm{FeCl}_{3}$ and $\mathrm{AlCl}_{3}$ at $\mathrm{pH} 5.8$ and $\mathrm{pH}$ 6.3, respectively. DOC removal was most efficient at a $\mathrm{pH}$ slightly lower than the $\mathrm{pH}$ of their minimum solubility because at this $\mathrm{pH}$, the hydrolysis products of $\mathrm{FeCl}_{3}$ and $\mathrm{AlCl}_{3}$ are mainly medium polymers or monomers, which have a high ability to remove DOC by complexation and charge neutralization. $\mathrm{PACl}$, one form of inorganic polymer flocculant, contains high level of charged polymeric Al hydrolysis products through pre-hydrolysis. The pre-formed medium polymer species $\left(\mathrm{Al}_{\mathrm{b}}\right)$ are highly stable, even after being dosed into a high alkalinity and $\mathrm{pH}$ water $[14,19]$. The performance of PACls in the treatment of high alkalinity water was investigated. DOC removal was correlated with $\mathrm{Al}_{\mathrm{b}}$ content in $\mathrm{PACl}$. However, it was observed that the flocs formed by $\mathrm{Al}_{\mathrm{b}}$ are small, with low settling efficiency. When overdose levels are used particles may re-stabilize due to the formation of positively charged small flocs, and particularly when high content $\mathrm{Al}_{\mathrm{b}}$ PACls are used [18].

In the context of attempting to address the disadvantages of $\mathrm{PACl}$, a new composite coagulant, HPAC (a modification of PACl that focuses on the efficient species of $\mathrm{Al}_{13}$, etc., and in combination of large composite polymer coagulation aids such as active silicates and cationic organic polymer) was developed. These additives are able to enhance both the charge neutralization and bridging properties of $\mathrm{PACl}[5]$.

Coagulation using HPAC for northern China waters was compared with three commonly used coagulants $\mathrm{FeCl}_{3}, \mathrm{AlCl}_{3}$ and $\mathrm{PACl}$, during different seasons [6,8]. The results of pilot-scale tests with $\mathrm{AlCl}_{3}, \mathrm{PACl}$ and $\mathrm{HPAC}$ were compared with the traditional coagulation strategy (a composite coagulant prepared using $\mathrm{FeCl}_{3}$, $\mathrm{NaSiO}_{3}$ [prepared before dosing in 1:1] and coagulant aid PDADMAC [ $\left.0.15 \mathrm{mg} \mathrm{L}^{-1}\right]$ ) at natural $\mathrm{pH}$ about 8.0 are shown in Fig. 8. The coagulant dose was $0.04 \mathrm{mM} \mathrm{Al} / \mathrm{Fe}$. HPAC was the most efficient in both NOM and turbidity (by flotation) removal. Residual turbidity by HPAC was reduced to as low as 0.27 NTU after flotation and 0.15 NTU after filtration, being much lower than other coagulants.

Tests at pilot-scale and at full-scale have shown that particles and NOM are removed synergistically with HPAC as coagulant by sequential treatment processes including pre-ozonation, coagulation, flotation and sand filtration $[6,8,20]$. The residual $\mathrm{Al}$ is relatively low [21]. Coagulant optimization such as by HPAC application can be considered as an alternative option to enhance NOM removal from high alkalinity and micro-polluted waters.

\subsubsection{Enhanced softening with coagulant}

Softening is employed in drinking water treatment primarily for the removal of polyvalent metallic ions, principally calcium and magnesium. Previous research indicates that only limited NOM removal can be achieved during the conventional softening process [13]. Even the use of high doses of lime $\left(200 \mathrm{mg} \mathrm{L}^{-1}\right)$ may not be effective to remove DBP precursors due to electrostatic repulsion arising from the high negative charge density of humic substances and the negatively charged calcium carbonate dense crystalline surface [22]. Unlike calcium carbonate, magnesium hydroxide precipitates as positively charged particles with an amorphous structure and larger surface area [13]. It has been found that a small increase in the magnesium precipitation results in a significant NOM removal [23]. Systems that remove at least $10 \mathrm{mg} \mathrm{L}^{-1} \mathrm{Mg}$ hardness as $\mathrm{CaCO}_{3}$ are proposed to be exempt from 
the enhanced softening requirements of the USEPA [2]. However, for typical concentrations of magnesium in raw water supplies, the precipitation of magnesium hydroxide requires a high $\mathrm{pH}$ (above 11), a condition uncommon in water treatment practice. It is not an attractive choice for softening plants. Addition of coagulant (e.g. activated silica, ferric chloride and organic polymers) during softening has been proposed as an alternative to enhanced NOM and particle removal [24].

The treatment of organic-polluted high-hardness surface water by enhanced softening via precipitation using $\mathrm{PACl}, \mathrm{FeCl}_{3}$ and $\mathrm{AlCl}_{3}$ has been investigated and reported in our previous paper [25]. It is found that higher removal of natural organic matter (NOM) $\left(\mathrm{UV}_{254}\right.$ removal reaches about $50 \%$ ) is achieved by enhanced softening with $\mathrm{PACl}$ addition as compared with conventional coagulation at natural $\mathrm{pH}$ or by softening alone without coagulation. PACl could enhance NOM removal more efficiently than $\mathrm{FeCl}_{3}$ and $\mathrm{AlCl}_{3}$ at relatively lower $\mathrm{pH}$ range $(\mathrm{pH}<10)$.

The performance of DOC, turbidity, $\mathrm{Ca}^{2+}$ and $\mathrm{Mg}^{2+}$ removal with or without $\mathrm{PACl}$ under softening conditions by $\mathrm{pH}$ adjustment using $\mathrm{NaOH}$ was investigated with source water LW in winter. The results are shown in Fig. 9.

With just the softening process alone (without $\mathrm{PACl}$ ), only minor DOC removal is observed at $\mathrm{pH}$ below 10 . With the use of $\mathrm{PACl}$ under the softening conditions, higher DOC removal is observed as compared with softening alone. At pH above 10, DOC removal is increased for both cases. The residual turbidities are significantly lower for softening with than without $\mathrm{PACl}$, in the $\mathrm{pH}$ range used.

$\mathrm{PACl}$ plays a complicated role in the process of $\mathrm{NaOH}$ softening. The PACl can increase the precipitation of magnesium through formation positively charged amorphous structure $\mathrm{Al}_{x} \mathrm{Mg}_{y}(\mathrm{OH})_{z}$ [26], and the residual $\mathrm{Mg}$ is lower than that of the $\mathrm{NaOH}$ softening without $\mathrm{PACl}$ (Fig. 9c). At the same time, the pre-formed positive charged polymer in $\mathrm{PACl}$ is relative stable at high $\mathrm{pH}$ [19]. On one hand, the $\mathrm{PACl}$ can act as coagulant to remove particle and NOM at high $\mathrm{pH}$ in softening process. On the other hand, it can act as cationic organic polymer to reform the surface charge property of the product of $\mathrm{CaCO}_{3}$ precipitate [27]. Under this circumstance, the $\mathrm{pH}$ for enhanced softening can be decreased significantly into the practical $\mathrm{pH}$ range for treatment plant operation.

The performance of enhanced softening is affected significantly by magnesium content in raw water [25]. For water with higher content of $\mathrm{Mg}^{2+}$, the inflexion $\mathrm{pH}$ for favorable NOM removal is lower. It is of practical value for organic-polluted water with high content of magnesium to be treated by enhanced softening with $\mathrm{PACl}$.

\section{Conclusion}

During this study, water qualities and coagulation features of typical North-China water were investigated, and some main conclusions can be drawn as follows.

(1) Source waters in North-China are seriously polluted by hydrophilic and low molecular weight organic matter, which is of high THMFP. It would pose serious health issue in disinfection process with $\mathrm{Cl}_{2}$, however it could not be removed favorably by traditional coagulation. Seasonal optimized coagulation targets for turbidity and NOM removals for North-China waters are proposed from Jar tests based on water characteristics.
(2) Three techniques that are beyond simple increasing of coagulant dose were demonstrated to achieve optimized coagulation. One is coagulation of the high alkalinity northern China water by adjusting the $\mathrm{pH}$ of raw water when metal salt coagulants $\left(\mathrm{FeCl}_{3}\right.$ and $\left.\mathrm{AlCl}_{3}\right)$ are used. The second is enhanced coagulation through coagulant optimization based on raw water characteristics. The third is enhanced softening with coagulant addition, especially with coagulant $\mathrm{PACl}$. This can enhance the formation of $\mathrm{Mg}(\mathrm{OH})_{2}$ precipitate at a relatively lower $\mathrm{pH}$ range $(\mathrm{pH}<10)$.

\section{Acknowledgements}

The authors are very grateful to the people of the Tianjin water treatment plant who provided full supports to this research. This research was funded by CNSF 50808001 and the National Key Technology R\&D Program of China (2006BAD01B03 and 2006BAD01B09), this project was supported by China Postdoctoral Science Foundation also.

\section{References}

[1] J.J. Rook, Water Treat. Exam. 28 (1974) 234-243.

[2] USEPA, Enhanced Coagulation and Enhanced Precipitative Softening Guidance Manual, EPA, Office of Water and Drinking Ground Water, Washington, DC, 1998.

[3] J.K. Edzwald, J.E. Tobiason, Water Sci. Technol. 40 (1999) 63-70.

[4] K. Carlson, S. Via, B. Bellamy, M. Carlson, J. Am. Water Works Assoc. 92 (2000) 63-75.

[5] M.Q. Yan, Enhanced coagulation and treatment system optimization for high alkalinity and micro-polluted water, Dissertation for Ph.D., Research Center for Eco-Environmental Sciences, Chinese Academy of Sciences, Beijing, 2006 (in Chinese).

[6] M.Q. Yan, D.S. Wang, J.R. Ni, J.H. Qu, C.W.K. Chow, Water Res. 42 (2008) 2278-2286.

[7] APHA AWWA WEF, Standard Methods for the Examination of Water and Wastewater, 19th edition, American Public Health Association, Washington, DC, 1995, pp. 253-258.

[8] M.Q. Yan, D.S. Wang, S.J. You, J.H. Qu, H.X. Tang, Water Res. 40 (2006) 3621-3627.

[9] G.L. Amy, R.A. Sierka, J. Bedessem, D. Price, L. Tan, J. Am. Water Works Assoc. 84 (1992) 67-75.

[10] J.G. Jacangelo, J. DeMarco, D.M. Owen, S.J. Randtke, J. Am. Water Works Assoc. 86 (1994) 64-77.

[11] J.K. Edzwald, W.C. Beker, L. Wattier, J. Am. Water Works Assoc. 77 (1985) $122-131$.

[12] D.M. Owen, G.L. Amy, Z.K. Chowdhury, R. Paode, G. McCoy, K. Viscosil, J. Am. Water Works Assoc. 87 (1995) 46-63.

[13] S.J. Randtke, J. Am. Water Works Assoc. 80 (1988) 40-56.

[14] M.Q. Yan, D.S. Wang, J.F. Yu, M. Edwards, J.H. Qu, Chemosphere 71 (2008) 1665-1673.

[15] J.E. Van Benschoten, J.K. Edzwald, Water Res. 24 (1990) 1519-1526.

[16] J.P. Croue, J.F. Debroux, G.L. Amy, G.R. Aiken, J.A. Leenheer, in: P. Singer (Ed.), Formation and Control of Disinfection By-products in Drinking Water., American Water Works Association, Denver CO., Denver, 1999, pp. 65-93.

[17] J.L. Weishaar, G.R. Aiken, B.A. Bergamaschi, M.S. Fram, R. Fujii, Environ. Sci. Technol. 37 (2003) 4702-4708.

[18] M.Q. Yan, D.S. Wang, J.H. Qu, W.J. He, C.W.K. Chow, J. Colloid Interface Sci. 316 (2007) 482-489.

[19] D.S. Wang, W. Sun, Y. Xu, H.X. Tang, J. Gregory, Colloid Surf. A 243 (2004) 1-10.

[20] M.Q. Yan, D.S. Wang, B.Y. Shi, M. Wang, Y. Yan, Chemosphere 69 (2007) 1695-1702.

[21] M.Q. Yan, D.S. Wang, B.Y. Shi, Q.S. Wei, J.H. Qu, H.X. Tang, J. Environ. Sci.: China 19 (2007) 271-277.

[22] G. Newcombe, C. Donati, M. Drikas, R. Hayes, Water Supply 14 (1994) 129-144.

[23] J.D. Thompson, M.C. White, G.W. Harrington, P.C. Singer, J. Am. Water Works Assoc. 89 (1997) 64-79.

[24] E. Coro, S. Laha, Water Res. 35 (2001) 1851-1854.

[25] M.Q. Yan, D.S. Wang, J.H. Qu, J.R. Ni, Y. Yan, C. Chow, Sep. Purif. Technol. 62 (2008) 402-407.

[26] S. Kvech, M. Edwards, Water Res. 36 (2002) 4356-4368.

[27] M. Bob, H.W. Walker, Colloid Surface A 191 (2001) 17-25. 